\title{
Correlation between acid, TBA, peroxide and iodine values, catalase and glutathione peroxidase activities of chicken, cattle and camel meat during refrigerated storage
}

\author{
Hamid Reza Gheisari \\ Department of Food Hygiene, \\ School of Veterinary Medicine, Shiraz University, Shiraz, I ran \\ Tel.: +98-7112286950; Fax: +98-7112286940; E-mail: ghaisari@shirazu.ac.ir
}

\begin{abstract}
The aim of this study was correlation determination between fat putrefaction indices and antioxidative enzymes in chicken, cattle and camel meat during refrigerated storage. Longissimus dorsi muscle of three Iranian dromedary one humped camel and three Holstein cattle and breast muscle of three broiler breeder chicken were obtained from the carcasses 3 days postmortem. The samples were ground and stored at $4{ }^{\circ} \mathrm{C}$ for 0,2 , or 4 days. Peroxide, TBA, acid and iodine values, catalase and glutathione peroxidase (GSH-Px) activities of the muscles were performed in each storage time. Catalase and GSH-Px activities were much higher in camel than in chicken and cattle and higher in cattle than in chicken. TBA value was lower in chicken than in camel. Camel had higher acid value than cattle. Chicken showed the highest and camel had the lowest iodine values. Catalase and GSH-Px activities and iodine values were quite stable during refrigerated storage. Acid values increased significantly over storage days in cattle. During the 4-day storage period, TBA and peroxide values increased. GSH-Px activity showed negative correlation with acid and TBA values in chicken and cattle. Acid value (for chicken and cattle) and peroxide value (for 3 animal species) showed positive correlation with TBA content. Iodine value had positive correlation with catalase activity in cattle and negative correlation with peroxide and TBA values in camel. In conclusion, our results indicate that peroxide and TBA values can be used as lipid quality indices in chicken, cattle and camel meat during 4 day storage in refrigerator.
\end{abstract}

Key Words: Chicken, Cattle, Camel, Meat, Lipid putrefaction, Refrigeration

\section{I ntroduction}

Fresh meat products are commonly marketed at refrigerated temperatures $\left(2-5{ }^{\circ} \mathrm{C}\right)$. However, many undesirable changes of the products can occur during refrigeration due to microbial growth and lipid oxidation, which give rise to quality reduction, meat spoilage, and economic loss. The oxidation of lipids leading to rancidity is one of the most important changes during food storage and production (Melton, 1983; Rosmini et al., 1996). Lipid oxidation leads to the formation of free radicals and hydroperoxides. Control and monitoring of lipid oxidation during meat processing or storage are important due to increased demand for precooked convenient meat products for home, fast food and institutional uses (Salih et al., 1987; Raharjo et al., 1992).

Endogenous antioxidant enzymes, especially catalase and GSH-Px, could potentially delay the onset of oxidative rancidity in stored meat. GSH-Px is a selenium-containing enzyme, catalyzing the reduction of lipid and hydrogen peroxides to less harmful hydroxides. The mammalian glutathione peroxidase family consists of at least four selenoproteins: cellular, extracellular, phospholipids hydroperoxide, and gastrointestinal GSH-Px (Arthur,
2000). Catalase is a heme-containing enzyme that catalyzes the decomposition of $\mathrm{H}_{2} \mathrm{O}_{2}$ to give $\mathrm{H}_{2} \mathrm{O}$ and $\mathrm{O}_{2}$ (Aebi, 1983; Claiborne, 1985). Removal of $\mathrm{H}_{2} \mathrm{O}_{2}$ by catalase inhibited oxymyoglobin oxidation in oxymyoglobin-liposome systems (Chan et al., 1997), prevented the formation of $\mathrm{H}_{2} \mathrm{O}_{2}$-activated metmyoglobin, that is regarded as a major factor in lipid oxidation in stored meat (Rhee, 1988).

The objectives of this study were correlation determination between acid, TBA, peroxide and iodine values, catalase and GSH-Px activities of chicken, cattle and camel muscles during refrigerated storage and the best lipid oxidation indicator selection in each animal species.

\section{Material and methods}

Animals and preparation of meat samples: Three Holstein cattle, three Iranian dromedary one humped camel and three Broiler breeder chicken were selected randomly. All animals were mature and female. Longissimus dorsi (LD) of camel and cattle and breast muscle of chicken were obtained from the carcasses 3 days postmortem, ground through a plate with $1.27 \mathrm{~cm}$ diameter holes, and reground through a plate with 0.32 $\mathrm{cm}$ holes. Forty gram portions of each animal meat 
were placed onto Petri dishes (diameter $=4 \mathrm{~cm}$, height $=1.5 \mathrm{~cm}$ ) and flattened. Each petri dish was over-wrapped with oxygen-permeable polyvinyl chloride film $\left(2325 \mathrm{ml} \mathrm{O} / \mathrm{mm} / \mathrm{m}^{2} / 24 \mathrm{~h}\right.$; thickness $=0.5$ $\mathrm{mm}$ ) and stored at $4{ }^{\circ} \mathrm{C}$ for 0,2 , or 4 days. Upon removal of the samples after each storage time, they were vacuum packaged and frozen at $-20{ }^{\circ} \mathrm{C}$ until analyzed (optimum 48 hour).

Assays of antioxidant enzymes: A 5-g muscle sample was homogenized in $25 \mathrm{ml}$ of phosphate buffer $(0.05 \mathrm{M}, \mathrm{pH}=7)$ and centrifuged at $4{ }^{\circ} \mathrm{C}$ for $2 \mathrm{~min}$ at $7000 \times \mathrm{g}$. The supernatant fraction was filtered through four layers of cheesecloth and used to determine catalase and GSH-Px activities.

Catalase activity assay was performed as described by Aebi (1983) and Mei, Crum, \& Decker (1994). One unit (U) of catalase was defined as the amount of extract needed to decompose $1 \mathrm{mmol}$ of $\mathrm{H}_{2} \mathrm{O}_{2}$ per min (Aebi, 1983; Mei et al., 1994).

GSH-Px activity was determined by measuring the oxidation of NADPH at $22{ }^{\circ} \mathrm{C}$ (DeVore and Greene, 1982; Gunzler and Flohe, 1985). One unit of GSH-Px was defined as the amount of extract required to oxidize $1 \mathrm{mmol}$ of NADPH per min at $22^{\circ} \mathrm{C}$.

Extraction of lipids: Meat ( $10 \mathrm{~g})$ was used for lipids extraction according to AOCS (1997). The percent of intramuscular fat was calculated from the weight of total lipid obtained after solvent extraction and the weight of the meat.

Determination of peroxide value: One of the most widely used tests for oxidative rancidity, peroxide value is a measure of the concentration of peroxides and hydroperoxides formed in the initial stages of lipid oxidation (Salih et al., 1989). The IDF standard method was used to determine the peroxide values of all samples. The extracted lipid of samples $(\leq 0.01-0.3$ g) was used (Shantha and Decker, 1994).

TBARS determination: The 2-thiobarbituric acid (TBA) method is the most widely used test for measuring the extent of lipid oxidation in muscle foods. The test is believed to measure the breakdown products of unsaturated fatty acid oxidation. Saturated aldehydes, 2-enals, and 2-dienals, produced in the termination phase of lipid oxidation, can be detected by reaction with 2 -thiobarbituric acid. The reaction produces a red color which can be measured using a spectrophotometer (Pikul et al., 1989; Gomes et al., 2003). TBARS was measured by the extraction method described by Vyncke (1975) with a few modifications. TBARS, expressed as micromole of malonaldehyde per kilogram of meat, was calculated using TEP/malonic aldehyde as standard .
Acid value: Acid value test measures free fatty acids as an indication of hydrolytic rancidity. Free acids in a fat (or fat extracted from a sample) can be determined by titration (Melton, 1983). Acid value was determined according to AOCS (1997). The acid value is the number of milligrams of sodium (or potassium) hydroxide necessary to neutralize the free acids in 1 gram of sample.

I odine value: While not a specific measure of fat stability, iodine number measures can indicate the potential of a fat to be oxidized. The method measures the reaction of iodine with double bonds of unsaturated fatty acids. Fats with a greater number of double bonds provide more sites for oxidation (Melton, 1983). The Hanus method, according to the AOCS (1997) was used. The iodine value of an oil or fat is defined as the mass of iodine absorbed by $100 \mathrm{~g}$ of the sample.

Myoglobin content: Myoglobin contents of the meat samples were measured spectrophotometrically by Kranen et al. method (1999).

Statistical analysis: The general linear models repeated measures of the SPSS software (version 15) was used for analysis. The different treatments were compared using the Tukey multiple range test. Calculation of pearson correlation coefficient was used to find relationship between factors that studied. Significance was established at $\mathrm{p}<0.05$.

\section{Results}

Fat content of cattle, camel and chicken meat were $5.35 \pm 0.60,7.95 \pm 1.49$ and $4.15 \pm 0.81$ percent, respectively. Camel had significantly higher fat than chicken meat. Myoglobin contents $(\mathrm{mg} / \mathrm{g}$ ) in camel meat $(3.64 \pm 0.42)$ and cattle meat $(3.18 \pm 0.54)$ were significantly higher than chicken meat $(0.31 \pm 0.07)$. Table 1 shows overall (over storage days) catalase and GSH-Px activities, TBARS, peroxide, acid and iodine values for chicken, cattle and camel meat. Catalase and GSH-Px activities were much higher in camel than in chicken and cattle and higher in cattle than in chicken. TBARS value was lower in chicken than in camel. Camel had higher acid value than cattle. Chicken showed the highest and camel had the lowest iodine values. For TBARS and peroxide values interactions between animal species and storage time were significant.

Changes in antioxidant enzyme activities, TBARS, peroxide, acid and iodine values during refrigerated storage of each animal species are shown in table 2. Catalase and GSH-Px activities and iodine values were quite stable during refrigerated storage. 
Table-1: Effects of animal species on catalase and glutathione peroxidase (GSH-Px) activities, TBARS, peroxide, acid and iodine values of chicken, cattle and camel meat ${ }^{\mathrm{a}}$

\begin{tabular}{llccccc}
\hline Animal Species & $\begin{array}{l}\text { Catalase } \\
(\mathbf{U} / \mathbf{g})\end{array}$ & $\begin{array}{c}\text { GSH-Px } \\
\mathbf{( U / g )}\end{array}$ & $\begin{array}{c}\text { TBARS } \\
(\boldsymbol{\mu m o l / K g )}\end{array}$ & $\begin{array}{c}\text { Peroxide Value } \\
(\mathbf{m E q O 2} / \mathbf{K g})\end{array}$ & Acid Value & Iodine Value \\
\hline Chicken & $142.67 \mathrm{a}$ & $1.09 \mathrm{a}$ & $0.066 \mathrm{a}$ & 0.08 & $82.11 \mathrm{ab}$ & $80.67 \mathrm{a}$ \\
Cattle & $441.67 \mathrm{~b}$ & $1.78 \mathrm{~b}$ & $0.131 \mathrm{ab}$ & 0.12 & $41.77 \mathrm{a}$ & $52.33 \mathrm{~b}$ \\
Camel & $480.17 \mathrm{c}$ & $1.92 \mathrm{c}$ & $0.204 \mathrm{~b}$ & 0.15 & $62.36 \mathrm{~b}$ & $40.43 \mathrm{c}$ \\
Se $^{\mathrm{b}}$ & 5.68 & 0.12 & 0.033 & 0.04 & 70.14 & 2.46 \\
\hline
\end{tabular}

a Means in the same column which are not followed by a common letter differ significantly $(P<0.05)$.

b S.E., standard error of the difference between animal species

Acid values increased significantly over storage days in cattle. During the 4-day storage period, TBARS and peroxide values increased.

GSH-Px activity showed negative correlation with acid value in chicken $(r=-0.95)$ and cattle $(r=-0.85)$. It had the same relationship with TBARS content (chicken: $r=-0.87$, cattle: $r=-0.86$ ). TBARS content showed positive correlation with acid value (chicken: $r=0.82$, cattle: $r=0.93$ ) and peroxide value (chicken: $r$ $=0.91$, cattle: $r=0.82$, camel: $r=0.87$ ). Iodine value had positive correlation with catalase activity in cattle $(\mathrm{r}=0.85)$ and negative correlation with peroxide $(\mathrm{r}=$ $-0.83)$ and TBARS $(r=-0.82)$ values in camel.

\section{Discussion}

Fresh meat undergoes major undesirable changes during storage at both refrigeration and freezing temperatures. Lipid peroxidation is one of the primary mechanisms of quality deterioration in stored foods, especially in muscle tissues. The changes in quality can be manifested by deterioration in flavor, color, texture, and nutritive value and the production of toxic compounds (Pearson et al., 1983). In the current study, peroxide, TBA and acid value measurements were chosen as representative of primary and secondary lipid oxidation and lipid hydrolysis, respectively. We didn't show any significant differences between peroxide values of 3 animal species. Camel had higher TBA value than chicken and cattle showed lower acid value than camel. Acid value (only for cattle meat), TBA and peroxide values increased significantly during storage time and they correlated positively with each other. Peroxides are intermediate reaction products, which will react further to form the odorous aldehydes and ketones indicative of oxidative rancidity. Peroxide formation during storage is low at first during an induction period, the length of which will depend on the nature of the fat and the presence of antioxidants, after which the rate of formation increases rapidly. Peroxide values are not static and care must be taken in handling and testing samples. It is difficult to provide a specific guideline relating peroxide value to rancidity. High peroxide values are a definite indication of a rancid fat, but moderate values may be the result of depletion of peroxides after reaching high concentrations. In highly unsaturated fats, even after extensive oxidation, the amount of peroxide remain low. This is because the peroxides initially formed from unsaturated fats are themselves highly unsaturated and thus unstable and react quickly to form secondary oxidation products. Low peroxide values may also be obtained for any extremely rancid products, again because the peroxides initially formed have all undergone further oxidation reactions (Levermore, 2004; Gotoh and Wada, 2006).

Free fatty acid content is a measure of the extent to which hydrolytic rancidity has occurred in a sample. It can be overestimated if other acid components are present in the system (such as amino acids in meat). Free fatty acids content is used extensively as a general indication of the condition and edibility of pure oils and fats and the fat extracted from food products, including meat (Levermore, 2004; Ogunsola and Omojola, 2008). The extent of oxidative rancidity in a fat may also be determined by its TBA number. The 2 thiobarbituric acid (TBA) test is believed to measure the breakdown products of unsaturated fatty acid oxidation. Typically, the TBA number of a sample shows a steady increase as it becomes more rancid, but a certain amount of variation is found between the TBA numbers obtained for similar fresh samples. As with peroxide value, a low TBA value is not an absolute indicator of fat quality. Aldehydes may have not yet formed or volatile aldehydes may have been lost during processing and storage (Pikul et al., 1989; Tokur etal., 2006).

In this study, chicken meat showed the higher iodine value than cattle and camel meat. Camel had the lower iodine value than cattle. Fats with a greater number of double bonds provide more sites for oxidation. Because other factors can influence fat 
Correlation between values and activities of meat during refrigerated storage

Table-2: Effects of storage time on catalase and glutathione peroxidase ( GSH-Px) activities, TBARS, peroxide, acid and iodine valuesa

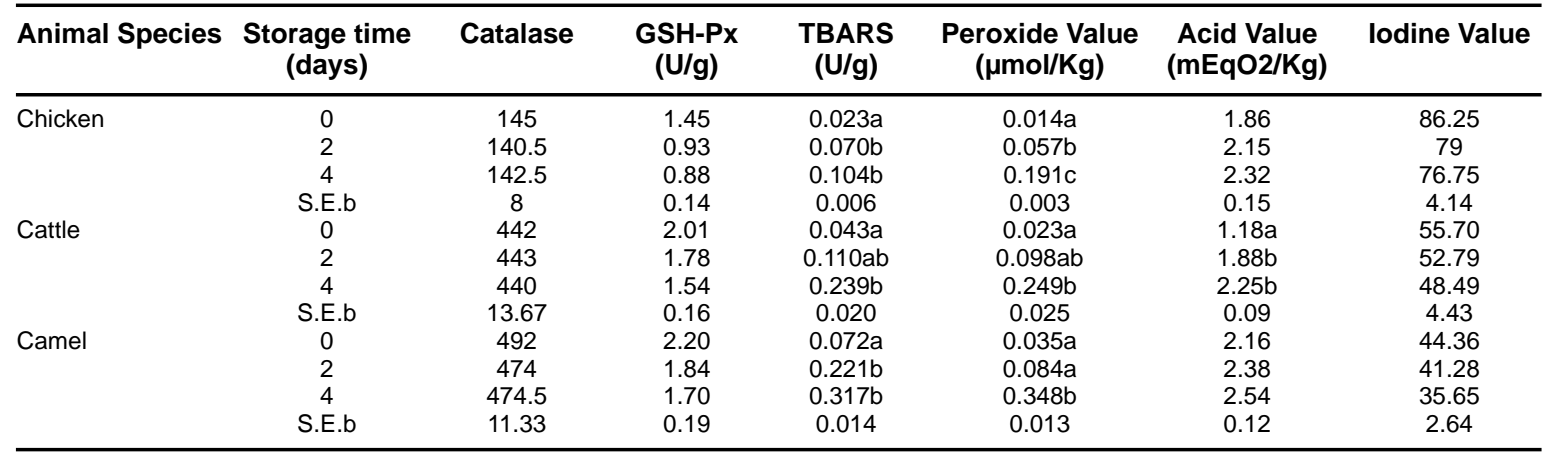

a Means in the same column which are not followed by a common letter differ significantly $(P<0.05)$.

b S.E., standard error of the difference between animal species

stability, iodine number is not useful by itself for predicting fat stability (Damodaran et al., 2006).

Muscle fibers can be categorized into different metabolic types: oxidative (red) or glycolytic (white), based on their chemical composition and enzyme activities (Lawrie, 2006). The oxidative muscles have more mitochondria and a higher content of myoglobin than the glycolytic ones. They mainly use fatty acids as substrates and have low activities of ATPase and phosphorylase, while the glycolytic muscles use mainly glycogen as an energy source and have higher activities of the latter enzymes. It is generally considered that oxidative muscles show higher activities of antioxidative enzymes than glycolytic muscles such as catalase and GSH-Px (DeVore and Greene, 1982; Lee et al., 1997; Renerre et al., 1996). This was also found in the present study for chicken breast muscles (glycolytic) in comparison with camel and cattle LD muscles (oxidative). In the present study, camel showed higher catalase activity than cattle. Pradhan, Rhee, \& Hernandez (2000) found higher catalase activity in pork LD muscle than in beef LD muscle. In their study, chicken thigh muscle showed higher catalase activity than breast muscle and similar to beef LD muscle. Comparison of GSH-Px activity in two muscle (oxidative and glycolytic) from chicken, turkey, duck, ostrich and lamb showed the highest activity in duck muscles.

Lamb psoas major had a significantly higher GSH-Px activity than chicken and turkey breast and ostrich fillet $(\mathrm{P}<0.05)$. Another interesting comparison to make was that between oxidative and glycolytic muscles for each species. In the oxidative muscles of chicken, duck, lamb and turkey, GSH-Px activities were significantly higher than those of the glycolytic muscles (Daun and Akesson, 2004).
Many researchers also reported higher lipid oxidation for beef muscles than for chicken breast meat (Rhee et al., 1996; Rhee and Ziprin, 2001). The difference in susceptibility to lipid oxidation between raw camel, cattle meat and chicken breast might be related to their heme pigment levels. Specifically, it was hypothesized that, since camel and cattle are higher in myoglobin content than chicken breast meat, more metmyoglobin and $\mathrm{H}_{2} \mathrm{O}_{2}$ would be formed in them through oxidation of oxymyoglobin, eventually resulting in more $\mathrm{H}_{2} \mathrm{O}_{2}$-activated metmyoglobin (ferrylmyoglobin radicals), thus accelerating lipid oxidation. The higher activity of the antioxidant enzymes could lead to a significant increase of resistance to lipid oxidation during meat storage. Such was the case in our study.

A few previous studies have indicated the stability of catalase in refrigerated chicken (Renerre $e t$ al., 1996), beef semimembranosus and pork boston butt muscles (Pradhan et al., 2000). The stability of catalase in refrigerated turkey varied with the type of muscle (Renerre et al., 1999). Our study has confirmed the catalase stability in refrigerated chicken, cattle and camel meat. The stability of catalase during frozen storage also has been reported in pork, beef and chicken muscles (Lee et al., 1997; Pradhan et al., 2000).

Our results showing a stability of GSH-Px activity in all animal species during refrigerated storage as same as other researches on fish (Watanabee et al., 1996), several beef muscles (Renerre et al., 1996), and beef psoas major and LD and pork LD muscles (Daun et al., 2001), which indicated stability of GSH-Px. However, our results were different from those on turkey Renerre et al., 1999.

In this study, GSH-Px activity correlated 
negatively with acid and TBARS values in chicken and cattle. GSH-Px is able to protect meat against oxidative damage, whereby it is possible to correlate GSH-Px activity with TBA values. Higher levels of GSH-Px activity may be expected to be associated with lower TBA numbers (Mei et al., 1994; DeVore et al., 1983; Maraschiello et al., 1999). In conclusion, our results indicate that peroxide and TBA values can be used as lipid quality indices in chicken, cattle and camel meat during 4 day storage in refrigerator.

\section{Acknowledgments}

This work was supported, in part, by funds from the school of veterinary medicine, University of Shiraz.

\section{References}

1. Aebi, H. E. (1983). Catalase. In H. U. Bergmeyer (Ed.), Methods of enzymatic analysis, Vol. 3 (pp. 273-286). Weinheim, Germany: Verlarg Chemie.

2. AOCS. 1997. Official methods and recommended practices. 5 th Ed. Commercial fats and oils. Washington, DC.

3. Arthur, J. R. (2000). The glutathione peroxidases. Cellular and Molecular Life Sciences, 57, 1825-1835.

4. Chan, W. K. M., Faustman, C., Yin, M. and Decker, E. A (1997). Lipid oxidation by oxymyoglobin and metmyoglobin with involvement of $\mathrm{H}_{2} \mathrm{O}_{2}$ and superoxide anion. Meat Science, 46, 181-190.

5. Claiborne, A. (1985). Catalase activity. In R. A. Greenwald (Ed.), CRC handbook of methods for oxygen radical rese arch, Vol. 1 (pp. 283-284). Boca Raton, Florida, USA: CRC Press.

6. Damodaran, S., et.al.(2006). Fennema's Food Chemistry, Fourth Edition, USA: CRC press.

7. Daun, C. and Akesson, B. (2004). Comparison of glutathione peroxidase activity, and of total and soluble selenium content in two muscles from chicken, turkey, duck, ostrich and lamb. Food Chemistry, 85, 295-303.

8. Daun, C., et.al. (2001). Glutathione peroxidase activity, tissue and soluble selenium content in beef and pork in relation to meat ageing and pig RN phenotype. Food Chemistry, 73, 313-319.

9. DeVore,V. R.,et. al.(1983). Thiobarbituric acid values and glutathione peroxidase activity in meat from chickens fed a selenium-supplemented diet. J. of Food Sci. 48,300-301.

10. DeVore, V.R. and Greene, B.E. (1982). Glutathione peroxidase in post-rigor bovine semitendinosus muscle. Journal of Food Science, 47, 1406-1409.

11. Gomes, H. A., et.al. (2003). Evaluation of 2-thiobarbituric acid method for the measuring of lipid oxidation in mechanically deboned gamma irradiated chicken meat. Food Chemistry, 80, 433-437.

12. Gotoh, N. and Wada, S. (2006). The importance of peroxide value in assessing food quality and food safety. Journal of the American Oil Chemists 'Society. 83(5), 473-474.

13. Gunzler, A. and Flohe, L. (1985). Glutathione peroxidase. In R. A. Greenwald (Ed.), CRC handbook of methods for oxygen radical research, Vol. 1 (pp. 285-290). Boca Raton, Florida, USA: CRC Press.

14. Kranen, R.W., et.al.(1999). Processing and products, Hemoglobin and myoglobin content in muscles of broiler chickens. Poultry Science, 78, 467-476.

15. Lawrie, R. (2006). Meat science (7th ed.). Cambridge, England: Woodhead publishing limited, CRC.

16. Lee, S.K., Mei, L. and Decker, E. A. (1997). Influence of sodium chloride on antioxidant enzyme activity and lipid oxidation in frozen ground pork. Meat Science, 46, 349-355.

17. Levermore, R. (2004). Rancidity in fresh and stored pork products. Meat International, 14(7), 16-18.

18. Maraschiello, C., et.al.(1999). Glutathione preoxidase activity. TBARS and a-tocopherol in meat from chickens fed different diets. J. of Agri. and Food Chemistry, 47(3), 867-872.

19. Mei, L., Crum, A. D. and Decker, E. A. (1994). Development of lipid oxidation and inactivation of antioxidant enzymes in cooked pork and beef. Journal of Food Lipids, 1, 273-283.

20. Melton, S. T. (1983). Methodology for following lipid oxidation in muscle foods. Food Technology, 37(7), 105-116.

21. Ogunsola, O.O. and Omojola, A.B. (2008). Nutritional Evaluation of a Dehydrated Shredded Meat Product, (Danbunama). Pakistan Journal of Nutrition, 7 (4), 554-556.

22. Pearson, A. M., et.al.(1983). Safety implications of oxidized lipids in muscle food. Food Technology, 37, 121-129.

23. Pikul, J., Leszczynski, D. E and Kummerow, F. A. (1989) Evaluation of three modified TBA methods for measuring lipid oxidation in chicken meat. Journal of Agriculture and Food Chemistry, 37 (5), 1309-1313.

24. Pradhan, A.A., Rhee, K.S. and Hernandez, P. (2000). Stability of catalase and its potential role in lipid oxidation in meat. Meat Science, 54, 385-390.

25. Raharjo, S., Sofos, J. N. and Schmidt, G. R. (1992). Improved speed, specificity, and limit of determination of an aqueous acid extraction thiobarbituric acid-C18 method for measuring lipid peroxidation in beef. Journal of Agriculture and Food Chemistry, 40, 2182-2185.

26. Renerre, M.,et.al.(1996). Antioxidant enzyme activities in relation to oxidation of lipid and myoglobin. Meat Science, 43, 111-121.

27. Renerre, M., et.al.(1999). Influence of dietary fat and vitamin $\mathrm{E}$ on antioxidant status of muscle of turkey. Journal of Agricultural and Food Chemistry, 47, 237-244.

28. Rhee, K. S. (1988). Enzymic and nonenzymic catalysis of lipid oxidation in muscle foods. Food Technology, 42(6), 127-132.

29. Rhee, K. S., Anderson, L. M. and Sams, A. R. (1996). Lipid oxidation potential of beef, chicken, and pork. Journal of Food Science, 61, 8-12.

30. Rhee, K.S. and Ziprin, Y.A. (2001). Pro-oxidative effects of $\mathrm{NaCl}$ in microbial growth-controlled and uncontrolled beef and chicken. Meat Science, 57, 105-112.

31. Rosmini, M. R., et.al.(1996). TBA test by an extractive method applied to 'Pate'. Meat Science, 42(1), 103-110.

32. Salih, A. M., et.al.(1989). Lipid degradation in turkey breast meat during cooking in storage. Poultry Science, 68, 754-761.

33. Salih, A. M., et.al.(1987). Modified extraction 2thiobarbituric acid method for measuring lipid oxidation in poultry. Poultry Science, 66, 1483-1488.

34. Shantha, N.C. and Decker, E.A. (1994). Rapid, sensitive iron-based spectrophotometric methods for determination of peroxide values of food lipids. Journal of AOAC International, 77(2), 422-425.

35. S. Wilfred Ruban, Kalaikannan. A and V. Appa Rao (2009). Physico-Chemical Characteristics of Pork Sausage during Refrigerated Storage Vet. World, 2009; 2(3):95-97.

36. Tokur, B., Korkmaz, K. and Deniz, A. (2006). Comparison of two thiobarbituric acid (TBA) method for monitoring lipid oxidation in Fish. E.U. J. of Fisheries \& Aquatic Sci., 23 (34), 331-334.

37. Vyncke, W. (1975). Evaluation of the direct thiobarbituric acid extraction method for determining oxidative rancidity in mackerel (Scomber scombrus L.). Fette-SeifenAnstrichmittel, 77, 239-240.

38. Watanabee, F., Goto, M., Abe, K. and Nakano, Y. (1996). Glutathione peroxidase activity during storage of fish muscle. Journal of Food Science, 61, 734-735, 782. 